\title{
Determinantes da inadimplência de pessoas físicas em cooperativa de crédito em Santa Catarina
}

\author{
Determinants of default of individuals in a credit union in Santa Catarina
}

\author{
Marilice Baldi $^{\mathbf{1}} \odot$, Giovani William Gianetti ${ }^{2} \odot$
}

Recebido: mar. 31, 2018

Aceito: nov. 02, 2020

${ }^{1}$ Gerente de Negócios - Rua Trajano Margarida, 144, ap 306 Trindade - 88036-050 - Florianópolis - SC - Brasil<licebaldi@ unochapeco.edu.br>.

${ }^{2}$ Mestre em Ciências (Economia Aplicada) - Avenida Pádua Dias, 11 - Agronomia - 13418-900 - Piracicaba - SP - Brasil.
Resumo: A inadimplência das operações de crédito é uma das principais preocupações das instituições financeiras, principalmente das cooperativas de crédito, já que impacta diretamente em seu resultado operacional. A adequada análise do perfil do associado e da operação de crédito contratada possibilita identificar, com maior assertividade, características que elevariam a probabilidade de inadimplência. O objetivo do presente estudo é identificar os principais fatores que afetam a inadimplência em operações de crédito de pessoa física em uma cooperativa de crédito de Santa Catarina. Para estimar a probabilidade de inadimplência utilizou-se um modelo de regressão logística, que considera explicitamente as características individuais dos associados e os atributos dos produtos de uma amostra de 13.079 operações de crédito da cooperativa. Entre as características individuais dos associados, o estado civil separado e a categoria profissional administrador estão relacionados à maior probabilidade de inadimplência. No que tange aos atributos os produtos, a probabilidade de inadimplência é mais elevada nas contratações da modalidade de crédito rural. Por fim, nota-se que as operações relativamente mais seguras estão concentradas em indivíduos do sexo feminino, bem instruídos, casados, com maior tempo de relacionamento com a cooperativa e que contratam crédito em modalidades que exigem contrapartida na forma de bens móveis ou imóveis.

Palavras-chave: cooperativismo; regressão logística; risco de crédito.

Este é um artigo publicado em acesso aberto (Open Access) sob a licença Creative Commons Attribution, que permite uso, distribuição e reprodução em qualquer meio, sem restrições desde que 0 trabalho original seja corretamente citado..

\begin{abstract}
The credit bankruptcy operations are one of the main concerns of financial institutions, especially credit unions, as it has a direct impact on their operating results. The adequate analysis of the associate's profile and the contracted credit operation makes it possible to identify, with greater assertiveness, characteristics that would increase the probability of bankruptcy. The objective of the present study is to identify the main factors that affect the bankruptcy in personal credit operations in a credit cooperative in Santa Catarina. To estimate the probability of bankruptcy, a logistic regression model was used, which explicitly considers the individual characteristics of the associates and the attributes of the products of a sample of 13,079 credit operations of the cooperative. Among the individual characteristics of the associates, the separate civil status and the professional administrator category are related to the greater probability of bankruptcy. Regarding the attributes of the products, the probability of default is higher in the contracting of the rural credit modality. Finally, it is noted that relatively safer operations are concentrated in well-educated, married individuals with a longer relationship with the cooperative and who contract credit in modalities that demand counterpart in the form of movable or immovable property.
\end{abstract}

Keywords: cooperativism; logistic regression; credit risk. 


\section{Introdução}

As cooperativas de crédito são instituições que prestam serviços de intermediação financeira exclusivamente a seus associados, com o objetivo de promover o desenvolvimento econômico e social, proporcionando serviços financeiros a custos inferiores em relação aos do sistema financeiro bancário tradicional (BACEN, 2018). Os cooperados, ao usufruírem dos produtos e serviços financeiros, tornam-se sócios e, ao mesmo tempo, donos da cooperativa (Singer, 2002).

Não obstante, a cooperativa de crédito distingue-se das demais instituições financeiras por apresentar o compromisso de priorizar, em sua política de crédito, determinadas finalidades sociais (ou classes de cooperados), com vistas ao desenvolvimento econômico regional (Singer, 2002). Nesse sentido, é pertinente compreender que, além dessa finalidade, sua política de crédito é baseada em valores que norteiam o cooperativismo, dos quais podemos destacar: solidariedade, liberdade, democracia, equidade, igualdade, responsabilidade, honestidade e transparência (Meinen e Port, 2014).

Para atender a tais finalidades e valores, as cooperativas de crédito precisam profissionalizar a gestão financeira, especialmente os aspectos relacionados à inadimplência e risco de crédito, uma vez que as cooperativas buscam realizar operações de crédito mais seguras, proporcionando maior retorno a todos os associados (Ferri, 2008). Segundo um levantamento realizado pela Confederação Nacional do Comércio de Bens, Serviços e Turismo (CNC), em setembro de 2018, o percentual de famílias endividadas aumentou de 59,6\%, em julho, para 60,7\%, em agosto; desse percentual, 23,8\% estavam inadimplentes (CNC, 2018). Diante do cenário de elevação do risco de crédito, as instituições financeiras têm adotado uma postura cautelosa, buscando conhecer melhor o perfil do associado na concessão do crédito (BACEN, 2018).

No início do século XX, o julgamento das operações de crédito era realizado de maneira mais subjetiva (Thomas et al., 2002). Com o passar do tempo modelos de análise de concessão de crédito começaram a ser adotados, buscando maior agilidade, menores riscos e maior assertividade na identificação da inadimplência (Camargo e Araújo, 2010). Um exemplo é o modelo de "credit scoring" que, para Berni (1999), consiste em uma técnica que gera uma pontuação para o cliente, a qual permite identificar e avaliar o limite de crédito baseado em uma série de fatores, como as operações liquidadas e o perfil de cada associado. Ademais, a literatura de finanças analisa três principais técnicas para a elaboração de um modelo de "crédito scoring": análise discriminante, análise logística e rede neurais (Amorim Neto e Carmona, 2004; Ferreira et al., 2011; Francisco et al., 2012; Thomas, 2000).

Para Blatt (1999), a classificação adequada do associado é fator fundamental para o retorno do crédito concedido. Para isso, é preciso entender as características do tomador, realizando uma pré-análise das variáveis relacionadas ao risco, ou seja, os chamados 6 C's do crédito: caráter (intenção de pagar a dívida), capacidade (potencial para quitar operações), capital (situação econômico-financeira), colateral (garantias complementares), condições (fatores externos, análise de concorrentes) e conglomerado (conhecer os controles, grupo econômico).

De maneira geral, a inadimplência traz consigo efeitos aos indivíduos, afetando as relações em sociedade, o estado psicológico e a vida familiar, ao mesmo tempo que impacta o ambiente macroeconômico, ampliando o risco das operações e os resultados dos produtos financeiros nas instituições de crédito (Trindade et al., 2012).

Na literatura econômica, carecem estudos que abordem a inadimplência de crédito no âmbito das cooperativas de crédito, principalmente para análises de pessoas físicas (Amorim Neto e Carmona, 2004). Alguns desses estudos contemplam amostras pequenas de indivíduos (Amorim Neto e Carmona, 2004; Lopes et al., 2017; Matos e Maciel, 2017). Ressalta-se que os efeitos macro e microeconômicos da inadimplência podem ter implicações relativamente mais adversas sobre as cooperativas de crédito do que os bancos, quando analisados dados amostrais com maior número de variáveis.

É nesse contexto que este estudo se insere, procurando identificar os principais fatores que afetam a inadimplência em operações de crédito de pessoa física em uma cooperativa de crédito de Santa Catarina. A contribuição deste estudo consiste em mostrar, além do perfil médio do inadimplente, como os atributos de produtos afetam a inadimplência. Além disso, o número de variáveis de controle e o número de observações individuais são relativamente maiores que alguns estudos, como os de Amorim Neto e Carmona (2004), Lopes et al. (2017) e Matos e Maciel (2017), o que resulta em estimativas mais confiáveis. 


\section{Material e Métodos}

0 trabalho foi desenvolvido a partir do método indutivo. O problema de pesquisa é abordado quantitativamente, que, segundo Richardson (1999), é o procedimento que se caracteriza pelo emprego de quantificação desde o processo de coleta de informações até a análise final. Além disso, esta pesquisa tem caráter descritivo, já que tem como objetivo descrever as características de uma amostra de operações de crédito em uma grande cooperativa de crédito, identificando as variáveis que afetam a probabilidade de inadimplência.

A técnica utilizada para estimar o modelo é o estimador de regressão logística (Logit). A regressão logística é utilizada para descrever o comportamento entre uma variável dependente binária e variáveis independentes métricas e não métricas (Gujarati, 2006).

Na regressão logística, a variável resposta é dicotômica, atribuindo-se o valor 1 ao acontecimento de interesse (sucesso) e 0 ao acontecimento complementar (insucesso). 0 fato da variável dependente ser binária (0 ou 1) possibilita associações de classificação dos fenômenos e interpretações em termos de probabilidade de o fenômeno investigado ocorrer ou não (Gujarati, 2006).

Nesse contexto, o modelo Logit é estimado a partir da variável (Y) qualitativa, que condiciona a situação de inadimplência a um conjunto de regressores exógenos. Os procedimentos técnicos para estimação do modelo podem ser consultados em Gujarati (2006).

0 modelo foi elaborado para identificar os fatores que influenciam a probabilidade de ocorrência de inadimplência em linhas de crédito de pessoas físicas. A seguir, com base em Gujarati (2006), é apresentada a especificação empírica geral do modelo a ser estimado (Equação 1):

$$
(p=\operatorname{Pr}[y=1 \mid x])=\frac{e^{x^{1} \beta}}{1+e^{x^{1} \beta}}
$$

onde, Y é a variável dependente que assume o valor de 1 caso o associado esteja inadimplente; caso contrário, $\mathrm{Y}$ assume o valor de $0 ; \beta$ é o vetor de parâmetros a serem estimados no modelo; $\mathrm{x}$ é o vetor de variáveis exógenas ou explicativas do modelo.

Para montar uma estratégia de identificação para os parâmetros do modelo econométrico, torna-se necessário estabelecer uma definição de inadimplência, uma vez que existem várias interpretações na literatura. Palmuti e Picchiai (2012), por exemplo, consideram inadimplentes os indivíduos com operações vencidas há mais de trinta dias. Selau e Ribeiro (2009), ao seu turno, consideram aqueles com operações vencidas há mais de sessenta dias.

A resolução 2.682 do Banco Central do Brasil (BACEN, 1999) prevê que as instituições financeiras classifiquem suas operações em níveis de risco e, em cada nível, efetuem o provisionamento conforme atrasos. Sendo assim, cada instituição dentro dos parâmetros abaixo pode estabelecer o nível para considerar um cliente inadimplente com base nos dias em atraso (Tabela 1).

Tabela 1. Níveis de provisão de riscos da resolução 2.682/99 do Banco Central do Brasil

\begin{tabular}{|c|c|c|}
\hline Nível & Provisão Mínima & Atraso \\
\hline & -- & ------- dias ------- \\
\hline AA & - & - \\
\hline A & 0,50 & - \\
\hline B & 1,00 & 15 a 30 \\
\hline C & 3,00 & 31 a 60 \\
\hline D & 10,00 & 61 a 90 \\
\hline$E$ & 30,00 & 91 a 120 \\
\hline $\mathrm{F}$ & 50,00 & 121 a 150 \\
\hline G & 70,00 & 151 a 180 \\
\hline $\mathrm{H}$ & 100,00 & $>180$ \\
\hline
\end{tabular}

Fonte: BACEN (1999) 
Nesta pesquisa, os associados inadimplentes foram caracterizados como indivíduos com atraso no pagamento de suas operações superior a 90 dias, classificados de acordo com a resolução 2.682/99 do Banco Central do Brasil, como risco nível "E" (BACEN, 1999). Após a classificação das operações de acordo com a qualidade do crédito, foram selecionados regressores que pudessem influenciar a situação de inadimplência dos associados em suas operações de empréstimos. As variáveis explicativas selecionadas compreendem o perfil dos associados e os atributos das modalidades de crédito, ou seja, dos produtos. A amostra é composta por 13.079 operações de crédito. Essa estratégia de identificação segue a abordagem clássica de McFadden (1974).

A Tabela 2 apresenta a variável dependente e o conjunto de regressores selecionados. Cada variável é classificada por tipo de dado (se ordinal ou contínua) e unidade de medida. Ademais, a descrição de cada regressor é acompanhada da definição de uma hipótese correspondente. Tal definição foi baseada na teoria de gestão de risco de crédito e na literatura empírica revisada anteriormente.

Para compilar os dados relacionadas à Tabela 2, utilizou-se o software Excel. Para a estimação do modelo econométrico, por sua vez, recorreu-se ao software Stata 14.

\section{A base de dados}

Foi realizado um levantamento de dados secundários em uma cooperativa de crédito de Santa Catarina, RS, que figura entre as maiores cooperativas de crédito do Brasil. A cooperativa possui 76 pontos de atendimento, mais de 170 mil associados, possui, ainda, aproximadamente $R \$ 1,2$ bilhões em operações de crédito e mais de R $\$ 2$ bilhões em ativos totais, de acordo com o balanço de junho de 2018. Apresenta a relação existente entre o capital próprio da instituição e o capital de terceiros, que está exposto a riscos por meio da carteira de crédito (índice de Basiléia) de 17,9\% (BACEN, 2018).

A base de dados é formada por uma amostra representativa do número de propostas em aberto na cooperativa, que contempla as operações de crédito realizadas até março de 2018, nas modalidades crédito pessoal, pré-aprovado, consignado, financiamento de bens e serviços e crédito rural (custeio e investimento). São 13.079 observações individuais para associados caracterizados como pessoa física. As operações de crédito utilizadas neste estudo estão relacionadas a três principais carteiras ofertadas pela cooperativa: crédito rural, empréstimo e financiamento.

O crédito rural abrange créditos destinados ao custeio e investimento. Os créditos de custeio são destinados a cobrir despesas habituais da produção até a colheita, e ofertados por um curto período (de 6 meses a 12 meses); os créditos de investimento são aplicados em bens ou serviços duráveis, com intuito de gerar maiores receitas ao associado (MAPA, 2018).

Os empréstimos representam um contrato entre o associado e a cooperativa, pelo qual os associados recebem uma quantia que deverá ser devolvida a cooperativa em prazo determinado, acrescida de juros acordados no momento da negociação. Os créditos de empréstimos não necessitam de destinação específica (BACEN, 2018). O financiamento também consiste em uma modalidade de empréstimo, porém deverá ter destinação específica do recurso tomado, como o financiamento de veículo, moto, máquina ou equipamento, bem como de bem imóvel, de modo que os bens ficam alienados a cooperativa até o final do contrato de financiamento (BACEN, 2018).

O único filtro realizado refere-se à definição de inadimplência. Associados que estavam com ação judicial e renegociações efetivas não foram considerados na amostra, sendo, portanto, excluídos da análise. 
Tabela 2. Variável dependente (inadimplência) e conjunto de regressores utilizados na estratégia de identificação do modelo econométrico

\begin{tabular}{|c|c|c|c|c|}
\hline Variável & Descrição & Tipo & Unidade & Expectativa \\
\hline Inadimplência & $\begin{array}{l}\text { Tomador que possui } \\
\text { operações em atraso a } \\
\text { mais de } 90 \text { dias. }\end{array}$ & Ordinal & $\begin{array}{l}0=\text { Adimplente; } \\
1=\text { Inadimplente. }\end{array}$ & Variável dependente. \\
\hline Renda & $\begin{array}{l}\text { Remuneração mensal } \\
\text { do associado. }\end{array}$ & Contínua & Escala logarítmica (R\$) & $\begin{array}{l}\text { Espera-se que o associado com maior renda } \\
\text { possua menor probabilidade de inadimplência } \\
\text { (Magro, Mondini e Hein, 2015). }\end{array}$ \\
\hline $\begin{array}{l}\text { Categoria } \\
\text { profissional }\end{array}$ & $\begin{array}{l}\text { Análise com base na } \\
\text { categoria de profissão } \\
\text { descrita no cadastro. }\end{array}$ & Ordinal & $\begin{array}{l}0 \text { = Aposentado; } \\
\text { 1= Do lar; } \\
2 \text { = Estudante/estagiário; } \\
3 \text { = Administrador } \\
4 \text { = Produtor rural; } \\
5 \text { = Outros. }\end{array}$ & $\begin{array}{l}\text { Espera-se que os aposentados possuam menor } \\
\text { probabilidade de inadimplência (Matos e } \\
\text { Maciel, 2017). }\end{array}$ \\
\hline Valor dos bens & $\begin{array}{l}\text { Bens móveis (veículos, } \\
\text { motocicletas, } \\
\text { equipamentos) e } \\
\text { imóveis (terrenos, casas, } \\
\text { apartamentos). }\end{array}$ & Contínua & Escala logarítmica ( $\mathrm{R} \$)$ & $\begin{array}{l}\text { Espera-se os associados que possuem } \\
\text { bens apresentem menor probabilidade de } \\
\text { inadimplência (Camargos et al., 2012); }\end{array}$ \\
\hline Estado civil & $\begin{array}{l}\text { Tipo de relação que } \\
\text { uma pessoa mantém. }\end{array}$ & Ordinal & $\begin{array}{l}0 \text { = Casado; } \\
1 \text { = Solteiro; } \\
2 \text { = Viúvo; } \\
3 \text { = Separado/divorciado. }\end{array}$ & $\begin{array}{l}\text { Espera-se que os solteiros possuam maior } \\
\text { probabilidade de inadimplência (Magro et al., } \\
\text { 2015). }\end{array}$ \\
\hline Gênero & Sexo do indivíduo. & Ordinal & $\begin{array}{l}0=\text { Masculino; } \\
1 \text { = Feminino }\end{array}$ & $\begin{array}{l}\text { Espera-se que os homens possuam maior } \\
\text { probabilidade de inadimplência (Ferreira et al. } \\
\text { 2011; Magro et al., 2015). }\end{array}$ \\
\hline $\begin{array}{l}\text { Grau de } \\
\text { instrução }\end{array}$ & $\begin{array}{l}\text { Nível de escolaridade } \\
\text { do associado. }\end{array}$ & Ordinal & $\begin{array}{l}0=\text { Analfabeto; } \\
1 \text { = Ensino Fundamental } \\
\text { Incompleto (EFI); } \\
2 \text { = Ensino Fundamental } \\
\text { Completo (EFC); } \\
3 \text { = Ensino Médio } \\
\text { incompleto (EMI); } \\
4 \text { = Ensino Médio } \\
\text { Completo (EMC); } \\
5 \text { = Superior incompleto } \\
\text { (ESI); } \\
6 \text { = Sup/Completo (ESC); } \\
7 \text { = Pós-graduado (POS). }\end{array}$ & $\begin{array}{l}\text { Espera-se que quanto mais anos de estudos, } \\
\text { menor seja a probabilidade de inadimplência } \\
\text { (Matos e Maciel, 2017). }\end{array}$ \\
\hline $\begin{array}{l}\text { Valor do } \\
\text { contrato }\end{array}$ & $\begin{array}{l}\text { Valor contratado da } \\
\text { operação de crédito. }\end{array}$ & Contínua & Escala logarítmica (R\$) & $\begin{array}{l}\text { Espera-se que quanto maior o valor da operação, } \\
\text { maior seja a probabilidade de inadimplência } \\
\text { (Lopes et al., 2017). }\end{array}$ \\
\hline Taxa de Juros & Taxa de juros mensal. & Contínua & Percentual (\%) & $\begin{array}{l}\text { Quanto maior a taxa de juros, maior a } \\
\text { probabilidade de inadimplência (Ferreira et al., } \\
\text { 2011). }\end{array}$ \\
\hline Prazo & $\begin{array}{l}\text { Quantidade de parcelas } \\
\text { da operação. }\end{array}$ & Contínua & Numérica & $\begin{array}{l}\text { Quanto maior o número de parcelas, maior a } \\
\text { probabilidade de inadimplência de um contrato } \\
\text { (Lopes et al., 2017). }\end{array}$ \\
\hline $\begin{array}{l}\text { Tempo de } \\
\text { cooperado }\end{array}$ & $\begin{array}{l}\text { Tempo de } \\
\text { relacionamento do } \\
\text { associado com a } \\
\text { cooperativa. }\end{array}$ & Contínua & Anos & $\begin{array}{l}\text { Quanto maior o tempo de relacionamento, menor } \\
\text { o risco de inadimplência do cooperado (Matos e } \\
\text { Maciel, 2017). }\end{array}$ \\
\hline $\begin{array}{l}\text { Modalidade } \\
\text { crédito }\end{array}$ & $\begin{array}{l}\text { Linhas de crédito } \\
\text { ofertadas subdivididas } \\
\text { em Crédito Rural, } \\
\text { Financiamento e } \\
\text { Empréstimo. }\end{array}$ & Ordinal & $\begin{array}{l}\text { Rural } \\
0 \text { = Custeio; } \\
1 \text { = Investimento. } \\
\text { Financiamento: } \\
0 \text { = Moto/veículo; } \\
1 \text { = Bens e serviços; } \\
2 \text { = Outros. } \\
\text { Crédito Pessoal: } \\
0 \text { = Consignado; } \\
1 \text { = Pré-aprovado; } \\
2 \text { = Crédito pessoal; } \\
3 \text { = Rotativo PF. }\end{array}$ & $\begin{array}{l}\text { Espera-se que o crédito rural possua maior } \\
\text { probabilidade de inadimplência, devido ao risco } \\
\text { climático (Donald,1976). }\end{array}$ \\
\hline Região & $\begin{array}{l}\text { Localização geográfica; } \\
\text { onde o associado reside. }\end{array}$ & Ordinal & $\begin{array}{l}0=\text { Oeste; } \\
1 \text { = Litoral; } \\
2 \text { = Vale; } \\
3 \text { = Outras regiões. }\end{array}$ & $\begin{array}{l}\text { Espera-se que residentes no litoral possuam maior } \\
\text { probabilidade de inadimplência, em Santa Catarina } \\
\text { (FECOMÉRCIO-SC, 2018). }\end{array}$ \\
\hline
\end{tabular}

Fonte: Resultados originais da pesquisa 


\section{Resultados e Discussão}

$\mathrm{Na}$ literatura empírica destacam-se alguns estudos que buscaram explicar, por meio de modelos econométricos, os fatores que influenciam na inadimplência de operações de crédito, entre eles destacamse: Palmuti e Picchiai (2012), Matos e Maciel (2017) e Ferreira et al. (2011). Além da teoria econômica e dos modelos de risco de crédito, esses estudos ajudam a justificar a escolha do conjunto de regressores do modelo, detalhados anteriormente (Tabela 2).

Amorim Neto e Carmona (2004) estimaram uma regressão logística e uma análise discriminante, com a finalidade de testar a eficiência dos modelos multivariados, como ferramentas eficazes no gerenciamento de crédito em operações de pessoas físicas. A análise contou com 344 indivíduos, classificados como adimplentes ou inadimplentes em um banco de varejo de Recife, Pernambuco. As variáveis do modelo foram cadastrais e compostas por clientes com operações de financiamento de veículo e com cartão de crédito. 0 modelo logístico apresentou uma taxa de sucesso de $81,7 \%$ e de análise descriminante de $81,4 \%$, sendo, ambas, significativas para o gerenciamento de crédito.

Palmuti e Picchiai (2012) utilizaram o modelo de regressão logística para avaliar os determinantes de inadimplência em operações do Crédito Produtivo Popular (FAEP), na região do Sul de Minas Gerais. 0 modelo apresentou ajuste satisfatório de $87,6 \%$. Os autores verificaram como variáveis de risco relevantes para determinar a probabilidade de inadimplência fatores como: valor liberado, grau de formalidade, renda, idade, valor da prestação, prazo e taxa de juros.

Matos e Maciel (2017) realizaram um estudo sobre a inadimplência bancária na região metropolitana de Fortaleza no ano de 2014, com base em 193 cadastros de pessoas físicas. Os autores mostraram, por meio da estimação de um modelo de probabilidade de inadimplência, que a ampliação do tempo de relacionamento, renda e grau de instrução são fatores que se relacionam negativamente com a probabilidade de inadimplência. Por outro lado, o estado civil casado e a idade afetam positivamente a probabilidade de inadimplência. 0 grau de ajuste do modelo foi estimado em $89 \%$.

Ferreira et al. (2011) buscaram identificar o perfil de clientes inadimplentes ou propensos a inadimplência, por meio da utilização de regressão logística, com base em informações de 158 clientes, pessoas físicas, de uma agência bancária situada na cidade de Viçosa, Minas Gerais. Os resultados mostraram que as variáveis sexo e escolaridade estão diretamente relacionadas a probabilidade de inadimplência: os homens são mais propensos à inadimplência do que as mulheres, e quanto maior o nível de escolaridade, menor a probabilidade de inadimplência. Por outro lado, as variáveis renda, tempo de residência, natureza da ocupação e idade, analisadas no modelo, não foram significativas. 0 grau de ajuste do modelo foi de $55 \%$.

Magro et al. (2015) realizaram uma pesquisa de abordagem quantitativa com 150 clientes que possuíam operações de crédito pessoal em maio de 2014, em uma cooperativa de crédito de livre admissão, localizada na região oeste de Santa Catarina, Rio Grande do Sul. O objetivo foi identificar o perfil dos clientes que possuem maior probabilidade de inadimplência. 0 resultado mostrou que a inadimplência está associada a pessoas mais jovens, do gênero masculino, solteiros e/ou divorciados, com rendimento mensal baixo e profissões relacionadas ao nível operacional.

Lopes et al. (2017) estimaram um modelo Probit, em 2015, com o propósito de identificar impactos na inadimplência em operações de crédito de pessoa física de uma instituição bancária de Ubá, Minas Gerais. Verificaram como variáveis de risco: consignado, tempo de conta, casado, taxa, prazo e crédito consignado. A análise mostrou elevado índice de inadimplência nas operações de consignado e para o perfil de cliente solteiro. O valor da operação e o prazo estão diretamente relacionados ao aumento da probabilidade de inadimplência. O modelo previu corretamente $92 \%$ das ocorrências de inadimplência e adimplência.

Donald (1976) analisou a inadimplência de operações em linhas de crédito rural, destacando que há uma associação à problemas climáticos ou estruturais. Analisou, também, as anistias como razão para descumprimento das operações. 0 que leva a inadimplência nas operações de crédito rural são as oscilações de preços, os níveis de produção e renda e os insumos utilizados no processo produtivo (Devany, 1984). 
Camargos et al. (2012) propuseram um modelo econométrico para estimar o risco de inadimplência em financiamentos concedidos em uma instituição financeira de Minas Gerais. A amostra selecionada conteve dados de 9.232 empresas, com características socioeconômicas e financeiras. 0 modelo classificou corretamente $88,5 \%$ das empresas e o resultado mostrou que o valor do financiamento é condicionante ao aumento da inadimplência, enquanto o valor dos bens dos avalistas e o tempo de relacionamento da empresa mostraram-se protetores contra a inadimplência.

A Pesquisa de Endividamento e Inadimplência do Consumidor (PEIC), realizada pela Federação do Comércio de Bens, Serviços e Turismo de Santa Catarina (FECOMERCIO), em fevereiro de 2018, mostrou que a capital de Santa Catarina, Florianópolis, é a cidade que possui o maior número de inadimplentes, com 21,6\% da população; e Blumenau é a cidade que possui o menor percentual de inadimplentes (FECOMERCIO-SC, 2018).

Eckert et al. (2013) verificaram, por meio de um estudo de caso em uma unidade da cooperativa de crédito Sicredi, em 2012, com base em quatorze operações de crédito inadimplentes, os fatores que levaram os tomadores a inadimplência. Os autores constataram que a maior probabilidade de inadimplência estava relacionada com a baixa escolaridade e inexistência de garantias nas operações.

\section{Estatística descritiva}

A Tabela 3 distribui as frequências relativas das variáveis qualitativas do modelo, tanto pelo total de operações, quanto pela classificação do saldo devedor.

Tabela 3. Distribuição das frequências absolutas e relativas das variáveis qualitativas do modelo

\begin{tabular}{|c|c|c|c|c|c|c|c|}
\hline \multirow[t]{2}{*}{ Variáveis } & & \multicolumn{2}{|c|}{ Adimplentes } & \multicolumn{2}{|c|}{ Inadimplentes } & \multicolumn{2}{|c|}{ Total } \\
\hline & & Freq. absoluta & Freq. relativa & Freq. absoluta & Freq. relativa & Freq. absoluta & $\begin{array}{l}\text { Freq. } \\
\text { relativa }\end{array}$ \\
\hline & & & -- \% -- & & -- \% --- & & ---- \% ---- \\
\hline & Total & 12.285 & 93,93 & 794 & 6,07 & 13.079 & 100,00 \\
\hline \multirow{2}{*}{ Gênero } & Masculino & 7.277 & 59,23 & 547 & 68,89 & 7.824 & 59,82 \\
\hline & Feminino & 5.008 & 40,77 & 247 & 31,11 & 5.255 & 40,18 \\
\hline \multirow{8}{*}{ Escolaridade } & Analfabeto & 2.300 & 0,19 & 0 & 0,00 & 23 & 0,18 \\
\hline & $\mathrm{EFI}$ & 1.684 & 13,71 & 109 & 13,73 & 1.793 & 13,71 \\
\hline & $\mathrm{EFC}$ & 1.130 & 9,20 & 64 & 8,06 & 1.194 & 9,13 \\
\hline & EMI & 721 & 5,87 & 83 & 10,45 & 804 & 6,15 \\
\hline & EMC & 5.548 & 45,16 & 415 & 52,27 & 5.963 & 45,59 \\
\hline & ESI & 665 & 5,41 & 42 & 5,29 & 707 & 5,41 \\
\hline & ESC & 2.239 & 18,23 & 76 & 9,57 & 2.315 & 17,70 \\
\hline & POS & 275 & 2,24 & 5 & 0,63 & 280 & 2,14 \\
\hline \multirow{6}{*}{ Ocupação } & Aposentado & 1.516 & 12,34 & 24 & 3,02 & 1.540 & 11,77 \\
\hline & Estudante & 13 & 0,11 & 0 & 0,00 & 13 & 0,10 \\
\hline & Administrador & 278 & 2,26 & 48 & 6,05 & 326 & 2,49 \\
\hline & Rural & 670 & 5,45 & 55 & 6,93 & 725 & 5,54 \\
\hline & Do lar & 21 & 0,17 & 1 & 0,13 & 22 & 0,17 \\
\hline & Outros & 9.787 & 79,67 & 666 & 83,88 & 10.453 & 79,92 \\
\hline \multirow{4}{*}{ Região } & Oeste & 6.760 & 55,03 & 345 & 43,45 & 7.105 & 54,32 \\
\hline & Litoral & 441 & 3,59 & 66 & 8,31 & 507 & 3,88 \\
\hline & Vale & 5.046 & 41,07 & 376 & 47,36 & 5.422 & 41,46 \\
\hline & Outros & 38 & 0,31 & 7 & 0,88 & 45 & 0,34 \\
\hline \multirow{4}{*}{ Estado civil } & Casado & 6.117 & 49,79 & 236 & 29,72 & 6.353 & 48,57 \\
\hline & Separado & 721 & 5,87 & 49 & 6,17 & 770 & 5,89 \\
\hline & Viúvo & 362 & 2,95 & 12 & 1,51 & 374 & 2,86 \\
\hline & Solteiro & 5.085 & 41,39 & 497 & 62,59 & 5.582 & 42,68 \\
\hline \multirow{3}{*}{ Carteira } & Crédito rural & 522 & 4,25 & 39 & 4,91 & 561 & 4,29 \\
\hline & Empréstimo & 6.889 & 56,08 & 545 & 68,64 & 7.434 & 56,84 \\
\hline & Financiamento & 4.874 & 39,67 & 210 & 26,45 & 5.084 & 38,87 \\
\hline
\end{tabular}

Fonte: Resultados originais da pesquisa

Nota-se que a maioria das operações de crédito da cooperativa concentrou-se no público de sexo masculino, que por sua vez representou o maior percentual de inadimplentes $(68,89 \%)$. Na mesma linha, 
verificou-se que $45,59 \%$ das operações de crédito foram contraídas por indivíduos com ensino médio completo. Entre os inadimplentes, tal percentual elevou-se para 52,27\%. Para níveis relativamente mais elevados de escolaridade, a frequência amostral foi superior à frequência de inadimplentes. Notou-se, por exemplo, que operações contraídas por indivíduos que possuem pós-graduação representaram $2,14 \%$ da amostra e $0,63 \%$ dos inadimplentes.

Entre as ocupações, administradores são $2,49 \%$ da amostra, mas quando analisada a frequência de inadimplentes, esse percentual se eleva para 6,05\%. Os trabalhadores rurais são $5,54 \%$ da amostra e, entre os inadimplentes representaram 6,93\%. Outras ocupações que comtemplam as demais profissões, representam $79,92 \%$ da amostra no total de operações e uma frequência de $83,88 \%$ das operações de crédito inadimplentes. Os aposentados que contraíram crédito representam $11,77 \%$ da amostra e, quanto à inadimplência, representam apenas 3,02\%.

Em termos de região, notou-se que as operações de crédito possuem maior concentração no oeste de Santa Catarina, isso se justifica por ser uma região com maior concentração de agências dessa cooperativa. Observou-se que, das operações de Santa Catarina, a região litoral possui o menor percentual do total de operações, equivalente a $3,88 \%$, justificado pelo menor número de agências instaladas na região, porém é a região que, atualmente, encontra-se em maior expansão de sua área de atuação. As demais regiões do Brasil possuem apenas $0,34 \%$ de significância no total de operações de crédito.

Na mesma linha de análise de região, considerando o grau de inadimplência, verificou-se que o oeste de Santa Catarina, embora possua maior número de operações de crédito, não possui o maior número de inadimplentes. Observou-se que a região do Vale concentrou o maior número de operações de créditos inadimplentes.

Da amostra, analisou-se o estado civil dos indivíduos e notou-se que embora os solteiros representem um percentual menor de operações de crédito $(42,8 \%)$ em relação aos casados, eles possuem percentual mais elevado de inadimplência (62,59\%).

Quanto às carteiras de crédito ofertadas pela cooperativa, a pesquisa foi subdividida em crédito rural, empréstimo e financiamento. Constatou-se que a maioria das operações realizadas concentraram-se em empréstimo, categoria que também concentra o maior percentual de inadimplentes. As operações de financiamento apresentaram uma participação na inadimplência inferior à sua representatividade na amostra. Notou-se que a participação relativa na inadimplência foi maior nas operações de crédito pessoal. Isso pode ser explicado pela falta de exigência de garantias reais, visto que na modalidade de financiamento há maior risco de o indivíduo perder o bem financiado, o que o incentiva a manter as parcelas regulares (Camargos et al., 2012).

A Tabela 4 apresenta algumas estatísticas descritivas para as variáveis quantitativas do modelo. Observou-se, pelos dados das operações de crédito da cooperativa, que os indivíduos que contraíram crédito possuem, em média, 40,13 anos de idade, renda média de $\mathrm{R} \$ 3,760.58$, tempo médio de relacionamento com a cooperativa de 3,8 anos, a taxa média de juros realizada nas operações foi de 2,17\% ao mês, o valor das operações foi bastante discrepante, uma vez que o desvio-padrão foi igual a $\mathrm{R} \$ 31.763,30$.

Quando se observa a fração de inadimplentes, esse perfil contempla menor média de idade (36,26 anos) e de tempo de relacionamento (2,75 anos), e apresentaram maior média de taxa de juros (3,18\%), quando comparada a fração de adimplentes.

A análise das médias coincidiu com a pesquisa realizada pela Serviço de Proteção ao Crédito (SPC, 2018), no primeiro semestre de 2018 , constatando que os adimplentes levam em conta a taxa de juros ao contratarem um empréstimo e os inadimplentes, por sua vez, preocupam-se, em primeiro lugar, com o valor da parcela. Observou-se que a taxa de juros varia muito entre os inadimplentes, conforme o desvio padrão da amostra. 
Tabela 4. Estatísticas descritivas das variáveis quantitativas

\begin{tabular}{|c|c|c|c|c|c|c|c|c|}
\hline Situação & Indicador & Renda & Idade & $\begin{array}{c}\text { Tempo de } \\
\text { relacionamento }\end{array}$ & $\begin{array}{l}\text { Taxa de } \\
\text { juros }\end{array}$ & Parcelas & Contrato & Saldo devedor \\
\hline \multirow{6}{*}{ Adimplentes } & & ---- R\$---- & anos & ---- anos ---- & ---- \% ---- & $---n^{0}---$ & ---- R\$---- & ---- R\$---- \\
\hline & Média & $3.764,30$ & 40,42 & 3,87 & 2,11 & 35,58 & $16.090,51$ & $12.510,06$ \\
\hline & Mediana & $2.100,00$ & 39,00 & 2,08 & 1,99 & 36,00 & $10.200,00$ & $7.266,58$ \\
\hline & $\begin{array}{l}\text { Desvio } \\
\text { padrão }\end{array}$ & $11.245,75$ & 14,60 & 4,71 & 0,86 & 16,94 & $31.763,30$ & $29.365,12$ \\
\hline & Máximo & $272.275,10$ & 90,00 & 32,00 & 5,99 & 146 & $1.159 .378,00$ & $1.062 .980,00$ \\
\hline & Mínimo & 0,00 & 18,00 & 0,00 & 0,08 & 1,00 & 131,60 & 2,53 \\
\hline \multirow{5}{*}{ Inadimplentes } & Média & $3.703,08$ & 36,26 & 2,75 & 3,18 & 28,93 & $13.490,51$ & $10.043,26$ \\
\hline & Mediana & $2.000,00$ & 34,00 & 1,65 & 2,90 & 24,00 & $5.375,89$ & $4.011,70$ \\
\hline & $\begin{array}{l}\text { Desvio } \\
\text { padrão }\end{array}$ & $16.081,71$ & 12,68 & 3,64 & 1,40 & 16,12 & $35.630,74$ & $24.300,83$ \\
\hline & Máximo & $375.229,40$ & 77,00 & 23,00 & 5,99 & 120,00 & $385.000,00$ & $283.406,10$ \\
\hline & Mínimo & 0,00 & 17,00 & 0,00 & 0,17 & 1,00 & 100,91 & 43,61 \\
\hline \multirow{5}{*}{ Total } & Média & $3.760,58$ & 40,13 & 3,80 & 2,17 & 35,71 & $15.932,67$ & $12.360,31$ \\
\hline & Mediana & $2.092,43$ & 38,00 & 2,08 & 2,00 & 36,00 & $10.000,00$ & $7.043,42$ \\
\hline & $\begin{array}{l}\text { Desvio } \\
\text { padrão }\end{array}$ & $11.596,15$ & 14,52 & 4,66 & 0,94 & 16,97 & $32.015,93$ & $29.088,00$ \\
\hline & Máximo & $375.229,40$ & 90,00 & 32,00 & 5,99 & 146,00 & $1.159 .378,00$ & $1.062 .980,00$ \\
\hline & Mínimo & 0,00 & 17,00 & 0,00 & 0,08 & 1,00 & 100,91 & 2,53 \\
\hline
\end{tabular}

Fonte: Resultados originais da pesquisa

\section{Análise da inadimplência nas linhas de crédito}

Os resultados apresentados na Tabela 5 foram obtidos a partir do modelo Logit, descrito anteriormente. No Logit, o coeficiente representa o logaritmo da razão de probabilidades, informando o sentido do impacto. 0 tamanho do impacto foi computado pelo efeito marginal, que na presente instância foi estimado no ponto médio da amostra. 0 grau de ajuste foi satisfatório, $93,96 \%$, e foi computado pelo percentual de acertos do modelo. Considerou-se a frequência com que o modelo previu corretamente que uma operação de crédito estava inadimplente, mais a frequência com que modelo corretamente previu a não inadimplência. 0 parâmetro de comparação foi fixado em 0,5. Dos artigos revisados na literatura, Lopes et al. (2017), Ferreira et al. (2011), Palmutti e Picchiai (2012) e Matos e Maciel (2017) tratam da maior qualidade do ajuste.

O modelo reportou significância estatística nas variáveis que medem atributos individuais: grau de instrução, gênero, categorias profissionais (aposentado e administrador), estado civil (separado e solteiro), tempo de relacionamento, regiãooeste e valor dos bens móveis e imóveis. Apresentou-se significância estatística nas variáveis que medem atributos dos produtos: linhas de crédito (consignado, empréstimo pessoal, pré-aprovado, custeio e investimento rural, financiamento de bens móveis), taxa de juros e valor do contrato. Em ambos os casos, pode-se inferir que variáveis nesses regressores ajudaram a explicar variações na probabilidade de inadimplência. Os níveis de significância das variáveis estão reportados na Tabela 5 .

Ao contrário do esperado, a renda não apresentou significância estatística ao nível de 10\%. Portanto, por meio da amostra e do modelo utilizado, não se pode rejeitar a hipótese nula do coeficiente estimado para essa variável. Apesar da expectativa de que a renda afetasse a probabilidade de inadimplência dos indivíduos, esse resultado não é unânime na literatura, por exemplo, Magro et al. (2015) mostraram que indivíduos com renda mais baixa apresentaram maior probabilidade de inadimplência, no entanto, Ferreira et al. (2011) mostraram que essa variável não foi estatisticamente significativa para explicar a probabilidade de inadimplência.

No que tange ao efeito marginal das variáveis relevantes, verificou-se que a elevação de um ciclo de instrução reduz a probabilidade de inadimplência em 0,6 pontos percentuais (p.p.), em relação à média. Tal resultado vai de encontro ao identificado pelo estudo de Matos e Maciel (2017). Pode-se inferir, portanto, que a elevação da escolaridade pode estar relacionada com a educação financeira, no sentido de que indivíduos escolarizados podem ter hábitos orientados para um planejamento financeiro sustentável. 
Tabela 5. Resultados do modelo Logit para análise da inadimplência em uma cooperativa de crédito de Santa Catarina

\begin{tabular}{|c|c|c|c|c|c|}
\hline Variáveis explicativas & & Coeficiente & Valor-p & Efeito marginal & Valor-p \\
\hline Constante & & $-3,2602^{* * *}$ & {$[0,000]$} & - & - \\
\hline Renda & & 0,0000 & {$[0,729]$} & 0 & {$[0,729]$} \\
\hline Instrução & & $-0,1244^{* * *}$ & {$[0,000]$} & $-0,0060^{* * *}$ & {$[0,000]$} \\
\hline Gênero & & $-0,3058^{* * *}$ & {$[0,001]$} & $-0,0144^{* * *}$ & {$[0,000]$} \\
\hline \multirow{4}{*}{ Ocupação } & Aposentado & $-1,2402^{* * *}$ & {$[0,000]$} & $-0,0423^{* * *}$ & {$[0,000]$} \\
\hline & Administrador & $0,6752^{* * *}$ & {$[0,000]$} & $0,0408^{* * *}$ & {$[0,003]$} \\
\hline & Rural & 0,3283 & {$[0,150]$} & 0,0176 & {$[0,190]$} \\
\hline & Do lar & 0,0695 & {$[0,947]$} & 0,0034 & {$[0,948]$} \\
\hline Idade & & $-0,0036$ & {$[0,369]$} & 0,0001 & {$[0,369]$} \\
\hline $\begin{array}{l}\text { Tempo de } \\
\text { Relacionamento }\end{array}$ & & $-0,0244^{*}$ & {$[0,090]$} & $-0,0012^{*}$ & {$[0,090]$} \\
\hline \multirow{2}{*}{ Bens patrimoniais } & Valor do bem imóvel & $0,0000^{*}$ & {$[0,050]$} & $0,0000^{* *}$ & {$[0,050]$} \\
\hline & Valor do bem móvel & $0,0000^{* *}$ & {$[0,032]$} & $0,0000^{* *}$ & {$[0,032]$} \\
\hline \multirow{3}{*}{ Região } & Oeste & $-1,0966^{* *}$ & {$[0,026]$} & $-0,0579^{*}$ & {$[0,050]$} \\
\hline & Vale & $-0,7015$ & {$[0,154]$} & $-0,0338$ & {$[0,161]$} \\
\hline & Litoral & $-0,5562$ & {$[0,276]$} & $-0,0229$ & [0.195] \\
\hline \multirow{3}{*}{ Estado civil } & Separado & $0,7744^{* * *}$ & {$[0,000]$} & $0,0479^{* * *}$ & {$[0,000]$} \\
\hline & Viúvo & 0,4118 & {$[0,223]$} & 0,0230 & {$[0,283]$} \\
\hline & Solteiro & $0,6655^{* * *}$ & {$[0,000]$} & $0,0327^{* * *}$ & {$[0,000]$} \\
\hline \multirow{7}{*}{ Modalidades de crédito } & $\begin{array}{l}\text { Empréstimo } \\
\text { consignado }\end{array}$ & $-1,1777^{* * *}$ & {$[0,000]$} & $-0,0439^{* * *}$ & {$[0,000]$} \\
\hline & Crédito pessoal & $-0,4889^{* *}$ & {$[0,015]$} & $-0,0230^{* *}$ & {$[0,013]$} \\
\hline & Pré-aprovado & $-1,3388^{* * *}$ & {$[0,000]$} & $-0,0457^{* * *}$ & {$[0,000]$} \\
\hline & Custeio rural & $2,0985^{* * *}$ & {$[0,000]$} & $0,1932^{* * *}$ & {$[0,000]$} \\
\hline & Investimento rural & $1,7785^{*}$ & {$[0,051]$} & 0,1551 & {$[0,203]$} \\
\hline & $\begin{array}{l}\text { Financiamento de } \\
\text { bens móveis }\end{array}$ & $-1,0484^{* * *}$ & {$[0,000]$} & $-0,0462^{* * *}$ & {$[0,000]$} \\
\hline & $\begin{array}{l}\text { Financiamento de } \\
\text { bens e serviços }\end{array}$ & $-0,1176$ & {$[0,642]$} & $-0,0055$ & {$[0,630]$} \\
\hline Taxa de juros & & $0,9698^{* * *}$ & {$[0,000]$} & $0,0472^{* * *}$ & {$[0,000]$} \\
\hline Prazo & & 0,0065 & {$[0,847]$} & 0,0003 & {$[0,847]$} \\
\hline Valor contratado & & $0,0000^{* * *}$ & {$[0,000]$} & $0000^{* * *}$ & {$[0,000]$} \\
\hline
\end{tabular}

Nota: Níveis de significância: * $10 \% ;{ }^{* *} 5 \%$; e ${ }^{* * *} 1 \%$

Em relação a variável gênero, ser mulher reduz a probabilidade de inadimplência em 1,45 p.p., em média (Tabela 5). $O$ resultado vai de encontro aos estudos de Ferreira et al. (2011) e Magro et al. (2015), revisados anteriormente. Em certo sentido, o resultado fornece aderência empírica para o argumento de que, em média, as mulheres possuem maior capacidade de planejamento financeiro do que homens. Em outros contextos, o resultado pode ser ainda mais relevante. Yunus (2006) desenhou a estrutura de incentivos do seu programa de microcrédito focalizando o papel da mulher na gestão financeira.

Quanto a variável de ocupação, as estimativas sugerem que estar aposentado reduz a probabilidade de inadimplência em -4,23 p.p., com relação à média (Tabela 5). Embora uma fração relativamente grande do crédito consignado esteja concentrada entre os aposentados, o efeito marginal encontrado foi mais geral. Esse resultado sugere que mesmo isolando o efeito crédito consignado, e outros cofatores como o valor contratado, ser aposentado reduziu a probabilidade de inadimplência. Pode-se se inferir que, entre os associados da cooperativa, os aposentados podem administrar relativamente melhor suas finanças.

A ocupação de administrador aumentou a probabilidade de inadimplência em 4,09 p.p., em média (Tabela 5). Embora tal resultado não encontre precedentes na literatura empírica, o efeito marginal relativamente elevado pode estar relacionado a uma predisposição ao risco, característica frequente entre os administradores. Segundo Keynes (1983), a disposição ao risco é parte importante do espírito animal que caracteriza o empresário, um dos elementos centrais da sua teoria da eficiência marginal do capital. Evidentemente, a sustentação de que o efeito marginal estimado está relacionado a essa predisposição ao risco merece uma investigação detalhada, porém, apesar de interessante, tal ponto é deixado para análise futura. 
Com relação ao tempo de relacionamento dos associados, notou-se que um ano adicional de relacionamento com a cooperativa diminui a probabilidade de inadimplência em 0,12 p.p. (Tabela 5). Tal evidência corrobora com o impacto estimado em outros estudos empíricos, como Matos e Maciel (2017), revisados anteriormente.

O efeito marginal da distribuição espacial dos associados também foi relativamente importante. Notou-se que residir no oeste de Santa Catarina reduz a probabilidade de inadimplência em -5,80 p.p., em relação à distribuição média (Tabela 5 ). 0 efeito pode ser influenciado não somente pelo perfil da gestão financeira executada pelo associado, mas também pelo fato de a sede da cooperativa ser na região oeste de Santa Catarina. Nesse sentido, a presença da gestão na região pode criar restrições informais ao comportamento inadimplente.

No que tange ao estado civil, ser separado elevou a probabilidade de inadimplência em 4,79 p.p. Ser solteiro, por sua vez, aumenta a probabilidade de inadimplência em 3,27 p.p., em relação à média (Tabela 5). Esse resultado corrobora a expectativa teórica e empírica inicial do modelo de Lopes et al. (2017) e Matos e Maciel (2017). Não obstante, como o estado civil casado foi a categoria de base do modelo, pode-se afirmar que os associados casados da cooperativa possuem uma probabilidade de inadimplência relativamente inferior às outras duas.

É interessante notar, na Tabela 5, que os atributos dos produtos contratados possuem efeitos marginais relativamente equiparáveis ou superiores às características individuais dos associados da Cooperativa. Nota-se que possuir operações de crédito consignado reduz a probabilidade de inadimplência em -4,39 p.p., em média. De acordo com Rodrigues et al. (2006), o crédito consignado possui menor probabilidade de inadimplência, porque possui taxas de juros relativamente menores, que são compensadas diretamente em folha, na conta do associado. Tal lógica parece ser invariante entre as diferentes instituições financeiras.

$\mathrm{Na}$ mesma linha, contrair uma operação de crédito pré-aprovado reduz a probabilidade de inadimplência em -4,57 p.p., em média. Isso se justifica pelo fato dessa modalidade ser liberada somente para associados que apresentem bom score financeiro, tendo esse requisito como critério de corte na liberação. Portanto, esse resultado pode apresentar um viés de seleção.

Possuir financiamento de bens móveis diminui a probabilidade de inadimplência em -4,62 p.p., em relação à média. 0 resultado sugere, para o contexto da gestão de crédito da cooperativa, que a alienação dos bens móveis é capaz de criar um "enforcement" para que o indivíduo honre com os pagamentos futuros. Portanto, o resultado corrobora com a expectativa inicial.

0 efeito marginal associado à modalidade de crédito custeio rural foi positivo. 0 resultado mostrou que uma operação de crédito rural aumentou a probabilidade de inadimplência em 19,32 p.p., em média (Tabela 5). Trata-se do maior efeito marginal estimado pelo modelo. Esses resultados corroboram as análises de Donald (1976) e Devany (1984), mencionadas anteriormente. Apesar disso, a carteira de crédito da cooperativa foi relativamente pouco concentrada no crédito rural, 4,29\% das operações totais (Tabela 3).

No que tange aos juros das modalidades de crédito, constatou-se que a elevação de um ponto percentual na taxa de juros aumenta a probabilidade inadimplência em 4,7 p.p. (Tabela 5). Ou seja, quanto maior a taxa de juros em uma operação, maiores as chances de inadimplência do tomador. Aparentemente, o resultado ilustra que taxas de juros relativamente elevadas podem ser obstáculos para a adimplência, pelo seu mecanismo de rolagem inerente. Contudo, o resultado possui importante ressalva: como a taxa de juros que incidirá sobre a operação de crédito será influenciada pelo "score" do associado, não é possível saber se o associado é inadimplente porque paga uma taxa de juros relativamente elevada, ou se paga uma taxa de juros relativamente elevada porque é um inadimplente à "ex ante".

Por fim, apesar de mostrar-se estatisticamente significativo, o valor do contrato, mesmo em escala logarítmica, apresenta efeito marginal suficientemente pequeno para explicar às variações na probabilidade de inadimplência. De certa forma, o valor do contrato é determinado pela capacidade de pagamento do associado.

O cadastro atualizado foi fundamental para a predição mais assertiva dos resultados, onde se observou que o perfil feminino com instrução mais acentuada, aposentados, com maior tempo de relacionamento com a cooperativa, residentes no oeste e casados, com operações de financiamentos 
com garantias reais de bens móveis, seriam o perfil mais adequado para que a cooperativa apresentasse baixas probabilidades de inadimplência em suas operações.

\section{Conclusões}

O estudo atinge o objetivo proposto, uma vez que o método utilizado mostrou-se eficiente para avaliar as características dos inadimplentes, classificando corretamente $93,96 \%$ das observações. A probabilidade de inadimplência em uma cooperativa de crédito em Santa Catarina é maior, principalmente, entre indivíduos com as seguintes características: homem com grau de instrução relativamente baixo, administrador de empresas, solteiro ou separado e que possui um tempo de relacionamento com a cooperativa relativamente baixo. Os atributos do produto contratado por esse indivíduo representativo também afetam a probabilidade de inadimplência: a não oferta de bens móveis em garantia, a contratação de modalidades de crédito que possuem taxas de juros relativamente elevadas e a contratação do crédito rural, ampliam as chances de inadimplência.

Como citar: Baldi, M.; Gianetti, G.W. 2021. Determinantes da inadimplência de pessoas físicas em uma cooperativa de crédito em Santa Catarina. Quaestum 2: e26750586

Contribuição dos autores: Concepção: Baldi, M.; Gianetti, G.W. Coleta de dados: Baldi, M. Análise dos dados: Baldi, M. Definição da metodologia: Baldi, M.; Gianetti, G.W. Redação e edição: Baldi, M.; Gianetti, G.W.

\section{Referências}

Amorim Neto, A.A.; Carmona, M.C.U. 2004. Modelagem do Risco de Crédito: um estudo do segmento de pessoas físicas em um banco de varejo. Revista eletrônica de administração, 10(4): 1413-2311.

Blatt, A. 1999. Avaliação de risco e decisão de crédito: um enfoque prático. Nobel, São Paulo, SP, Brasil.

Berni, M.T. 1999. Operação e concessão de crédito: os parâmetros para a decisão de crédito. Atlas, São Paulo, SP, Brasil.

Banco Central do Brasil (BACEN). 1999. Resolução do Conselho Monetário Nacional nº 2.682 de 21 de dezembro de 1999. Dispõe sobre critérios de classificação das operações de crédito e regras para constituição de provisão para créditos de liquidação duvidosa. Diário Oficial da União, Brasília, DF, 23 dez. 1999. Disponível em: <https:// www.bcb.gov.br/pre/normativos/res/1999/pdf/res_2682_v2_L.pdf>. Acesso em: out. 10, 2018.

Banco Central do Brasil (BACEN). 2018a. O que é cooperativa de crédito. Disponível em: <http://www.bcb.gov.br/ pre/composicao/coopcred.asp>. Acesso em: jun. 10, 2018.

Banco Central do Brasil (BACEN). 2018b. Relatório de Estabilidade Financeira. Disponível em: <https://www.bcb. gov.br/htms/estabilidade/2018 04/refPub.pdf>. Acesso em: 18 jun. 2018.

Banco Central do Brasil (BACEN). 2018c. Relatório Conglomerado Prudencial. Disponível em: <https://www3.bcb. gov.br/ifdata/>. Acesso em: out. 02, 2018.

Banco Central do Brasil (BACEN). 2018d. Índices de Basiléia e Imobilização. Disponível em: <https://bancodata. com.br/relatorio/78825270/>. Acesso em: out. 02, 2018a.

Banco Central do Brasil (BACEN). 2018e. Empréstimos e financiamentos. Disponível em: <https://www.bcb.gov. br/pre/bc atende/port/servicos9.asp>. Acesso em: maio 01, 2018b.

Camargo, M.C.S.; Araújo, E.L.T. 2010. Fatores Condicionantes de Inadimplência em Processos de Concessão de Crédito a Micro e Pequenas Empresas do Estado de Minas Gerais. RAC eletrônica, 14: 333-352.

Camargos, M.A.; Camargos, M.C.S.; Araujo, E.A. 2012. A inadimplência em um programa de crédito de uma instituição financeira pública de Minas Gerais: uma análise utilizando regressão logística. REGE Revista de Gestão, 19(3): 467-486.

Confederação Nacional do Comércio de Bens, Serviços e Turismo (CNC). 2018. Pesquisa Endividamento e Inadimplência do Consumidor. Disponível em: <http://cnc.org.br/sites/default/files/arquivos/analise peic agosto_2018.pdf>. Acesso em: set. 10, 2018.

Devany, A.S. 1984. Comment on Modeling in banking firm: a survey. Journal of Money, Credit and Banking, 16: 603-609.

Donald, G. 1976. Credit for small farmers in developing Countries. Westview Press, Bouder, Colorado, USA.

Eckert, A.; Mecca, M.S; Biasio R.; Consorte A.S. 2013. Principais causas da inadimplência de pessoas físicas junto a uma cooperativa de crédito: estudo de caso em uma unidade do Sicredi. Revista de Administração e Negócios da Amazônia, 5(1): 59-70.

Francisco, J.R.S. 2012. Risco de crédito em cooperativas: uma análise com base no perfil do cooperado. Sociedade, contabilidade e gestão, 7(2): 137-149.

Federação do Comércio de Bens, Serviços e Turismo de Santa Catarina. (FECOMERCIO-SC). 2018. Pesquisa de Endividamento e Inadimplência do Consumidor PEIC. Disponível em: <file:C:/Users/liceb/Downloads/PEICfevereiro-2018.pdf>. Acesso em: out. 13, 2018.

Ferreira, M.A.M.; Oliveira, M.O.; Santos, L.M.; Abrantes, L.A. 2011. Previsão de risco de crédito para definição do perfil de clientes de um banco de varejo. Revista de Negócios, 16(2): 47-64.

Ferri, G. 2008. Why cooperative banks are particularly important at a time of credit crunch. European Association of Co-operative Banks, Bari, Roma, Italia.

Gujarati, D. 2006. Econometria básica. 4ed. Campus, Rio de Janeiro, RJ, Brasil.

Keynes, J.M. 1983. A Teoria Geral do Emprego, do Juro e da Moeda. Abril Cultural, São Paulo, SP, Brasil.

Lakatos, E.M.; Marconi, M.A. 2010. Metodologia Científica. 5ed. Atlas, São Paulo, SP, Brasil.

Lopes M.G.; Ciribeli, J.P.; Massardi, W.O.; Mendes, W.A. 2017. Análise dos indicadores de inadimplência nas linhas 
de crédito para pessoa física: um estudo utilizando modelo de regressão logística. Estudos do CEPE, 46: 75-90. Magro, C.B.D.; Mondini, V.E.D.; Hein, N. 2015. Gestão dos Riscos de Inadimplência dos Tomadores de Crédito: Um Estudo em uma Cooperativa de Crédito. Pensar Contábil, 17(62): 55-63.

Matos M.H.; Maciel, W.M. 2017. Análise da Inadimplência Bancária: um estudo de caso da região Metropolitana de Fortaleza. Revista Conexões Ciência e tecnologia, 11: 12-23.

McFadden, D. 1974. Conditional logit analysis of qualitative choice behavior. p. 105-142. In: Zarembka, P. (Ed.). Frontiers in Econometrics. Academic Press, New York, NY, USA.

Meinen, Ê.; Port, M. 2014. Cooperativismo Financeiro: percurso histórico, perspectivas e desafios. Confebras, Brasília, DF, Brasil.

Ministério da Agricultura, Pecuária e Abastecimento (MAPA). 2018. Crédito Rural. Disponível em: <http://www. agricultura.gov.br/assuntos/politica-agricola/credito-rural.>. Acesso em: jun. 23, 2018.

Palmuti, C.S; Picchiai, D. 2012. Mensuração do risco de crédito por meio de análise estatística multivariada. Revista Economia Ensaios. Uberlândia, 26(2): 7-22.

Richardson, R. 1999. Pesquisa social: métodos e técnicas. Atlas, São Paulo, SP, Brasil.

Rodrigues, E.A.S.; Chu, V.; Alencar, L.S.; Takeda, T. 2006. O efeito da consignação em folha nas taxas de juros dos empréstimos pessoais. Banco Central do Brasil. Trabalhos para discussão. Brasília, DF. 108: 1-30. Disponível em: <https://www.bcb.gov.br/pec/wps/port/wps108.pdf>. Acesso em: nov. 02, 2018.

Selau, L.P.R.; Ribeiro, J.L.D. 2009. Uma sistemática para construção e escolha de modelos de previsão de risco de crédito. Revista Gestão e Produção, 16(3): 398-413.

Serviço de Proteção ao Crédito (SCPC). 2018. Pesquisa perfil do consumidor. Disponível em: <https://www. boavistaservicos.com.br/noticias/adimplentes-avaliam-taxa-de-juros-e-inadimplentes-o-valor-da-parcelaao-contratar-emprestimo-para-quitar-dividas-apura-boa-vista-scpc/>. Acesso em: jul. 01, 2018.

Singer, P. 2002. Introdução à Economia Solidária. Editora Fundação Perseu Abramo, São Paulo, SP, Brasil.

Thomas, C.L. 2000. A survey of credit and behavioural scoring: forecasting financial risk of lending to consumers. International Journal of Forecasting, 16(2): 149-172.

Thomas, L.C.; Crook, J.; Edelman, D. 2002. Credit scoring and its applications. SIAM, Philadelphia, USA.

Trindade, L.L.; Righi, M.B.; Vieira, K.M. 2012. De onde vem o endividamento feminino? Construção e validação de um modelo PLS-PM. Read Revista Eletrônica de Porto Alegre, 18(3).

Yunus, M.; Jolis, A. 2006. O banqueiro dos pobres. Ática, São Paulo, SP, Brasil. 